\title{
Non-pharmacological pain management in the neonatal intensive care unit: Managing neonatal pain without drugs
}

\author{
Oana Bucsea, Rebecca Pillai Riddell* \\ York University, Office of the Vice-President Research \& Innovation, 509 Kaneff Tower, 4700 Keele Street, Toronto, ON, M3J 1P3, Canada
}

\section{A R T I C L E I N F O}

\section{Keywords:}

Pain

Neonate

Risk

Pain management

Non-pharmacological

Neonatal intensive care unit

Biopsychosocial

\begin{abstract}
A B S T R A C T
Premature infants hospitalized after birth are exposed to repeated painful procedures as part of their routine medical care. Early neonatal exposure to unmanaged pain has been linked to numerous negative long-term outcomes, such as the development of pain hypersensitivity, detrimental psychological symptomology, and altered neurodevelopment. These findings emphasize the crucial role of pain management in neonatal care. The aim of this article is to give an overview of evidence-based non-pharmacological pain management techniques for hospitalized neonates. Research supporting the effectiveness of various proximal, distal, and procedural pain management methods in neonates will be presented. Additionally, understanding the larger biopsychosocial context of the infant that underpins the mechanisms of these pain management methods is essential. Therefore, two important models that inform non-pharmacological approaches to infant pain management (DIAPR-R [The Development of Infant Acute Pain Responding-Revised], Attachment Theory) will be discussed.
\end{abstract}

For infants born preterm, painful medical procedures are a routine part of their medical care. Research has demonstrated that approximately $7 \%$ of newborns are hospitalized after birth [1] and are subsequently exposed to repeated painful procedures. Previous research has found that neonates in NICUs experience an average of 7.5-17.3 daily painful procedures [2]. Approximately $70 \%$ of medical procedures carried out on neonates in the NICU are classified as painful [3]. Additionally, both preterm and term newborns requiring more intensive care, such as respiratory support, are exposed to an increased amount of acute procedures [4]. While it was previously believed that newborns did not feel pain [5], research findings have not only refuted this belief [6], but have also revealed that newborns' threshold for pain is likely lower than that of older infants and children [7] due to developing abilities to modulate pain both cognitively and physically. Moreover, preterm neonates' pain thresholds are seen as substantially lower than full-term newborns [7]. Given the ubiquitous nature of painful and invasive medical procedures in the NICU $[8,9]$, the implications of repetitive painful procedures have also been studied in the literature.

Preterm newborns' length of NICU stay and amount of early exposure to painful procedures are predictive of detrimental psychological symptoms, such as somatization and internalizing symptoms, during their preschool and school years [10,11]. Early neonatal exposure to unmanaged pain has also been linked to altered neurodevelopmental outcomes in school aged children, such as thinner cortical regions, predominantly those associated with the frontal and parietal lobes [12]. In addition to undermanaged acute pain leading to highly distressing procedures for newborns, research has linked early pain exposure with multiple adverse long-term effects, relating to both subsequent pain reactivity and mental health outcomes. For instance, infants demonstrate a subsequent hypersensitivity to pain with early exposure to painful procedures [13,14]. This also leads to higher distress reactivity perceiving subsequent non-noxious procedures, such as diaper changes, as painful [15].

It is unequivocal that neonates are exposed to an abundance of iatrogenically painful procedures during an exquisitely sensitive period of development, which results in long-term implications that scientists and clinicians are only beginning to understand. Pain management is a critical factor to understand in neonatal care. This article will discuss pain management strategies that focus on cognitive, behavioural and contextual approaches. However, while pain management strategies will be presented, understanding the larger biopsychosocial context of the infant that helps to explain the mechanisms of these approaches is of primary importance. Two important models that should inform nonpharmacological approaches to infant pain management (DIAPR-R [The Development of Infant Acute Pain Responding-Revised], Attachment Theory) will be discussed to set a foundation.

\footnotetext{
* Corresponding author.

E-mail address: rpr@yorku.ca (R. Pillai Riddell).

URL: http://www.yorku.ca/ouchlab (R. Pillai Riddell).

@drbeccapr (R. Pillai Riddell)
} 


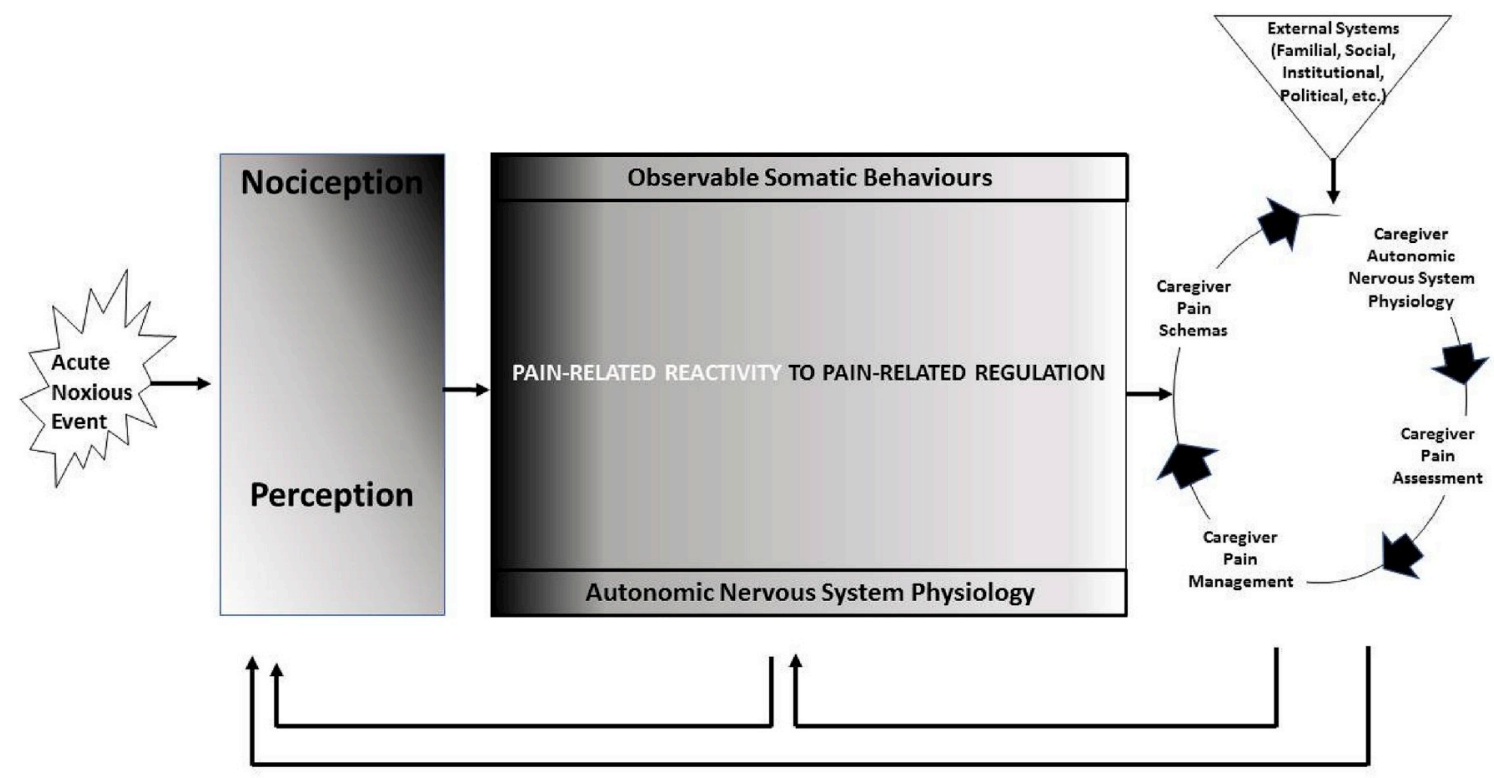

Figure X: The Development of Infant Acute Pain Responding-Revised (DIAPR-R)

Fig. 1. The Development of Infant Acute Pain Responses- Revised (Pillai Riddell 2018, as cited in Goubert, Pillai Riddell, Simons and Borsook, in press).

\section{A biopsychosocial model of infant acute pain: the DIAPR-R model}

In order to effectively manage infant acute pain, the underlying biological, cognitive, emotional, and social aspects of the pain experience must be understood. Currently, there is only one biopsychosocial model designed to specifically understand infant acute pain from a biopsychosocial perspective - the DIAPR-R [ [16], See Fig. 1]. While based on an extensive program of longitudinal research with the OUCH Cohort (www.yorku.ca/ouchlab) with healthy infants over the first year of life, the relevance to the preterm child is strong. A few key features of the DIAPR-R model deserve highlighting. First, similar to the first version of the model [17], it purports that infants are biologically predisposed to seek the help of others in times of distress. Lacking the physical and cognitive capacity to protect themselves from danger, during periods of distress (such as pain), infant responding must be taken into the context of caregiving. New to the model, based on collaborative work with a neurophysiological research group (Fitzgerald lab, University College London), the model took a stronger attempt to speculate and present the nuances of the biological processing of the event.

Immediately following the painful event, the DIAPR-R model illustrates the progression of the pain response, from the initial nociception (marked by the cascade of events from the peripheral nociceptor to the first afferent signals in the primary and secondary somatosensory cortex), to the perception of the painful stimulus (characterized by the widespread cortical activation in areas such as the prefrontal cortex, anterior cingulate cortex, insular cortex, and the amygdala), which are associated with the process of making sense of the initial response in the somatosensory cortex [18]. These initial processes combine to inform the infants' pain-related reactivity response, which subsequently transitions into a pain-related regulation response as the child returns to baseline distress levels. This sequence from nociception and perception to pain-related reactivity followed by pain-related regulation is additionally impacted by the caregiver context, such as the caregivers' cognitions (e.g., pain schemas and assessments), as well as their responses (e.g., caregivers' ANS physiological responses and their engagement in pain management strategies). As aforementioned, the caregiver context is particularly important in neonates, due to their inability to engage in self-directed regulation strategies, thus making it necessary for them to rely on sources of external distress regulation $[19,20]$. Moreover, on a broad level, the DIAPR-R model also depicts the infants' larger systemic influences (e.g., culture) as exerting an effect on their pain response via the caregiver [21]. Importantly, the model uses feedback loops to demonstrate the mechanisms via which the caregiver context and the non-immediate pain response feedback on the nociception and perception of pain.

The new DIAPR-R model borrows heavily on a fundamental principle from decades of work in developmental psychology on the Attachment System. Initially formulated by Bowlby [22,23] and operationalized by Ainsworth et al. [24] and Main \& Solomon [25], the attachment relationship, i.e. the way in which a child has been socialized by a caregiver throughout early childhood regarding how to involve them to regulate distress, is critical to integrate when understanding psychological (cognitive, behavioural, contextual) perspectives to infant pain management. The next section provides more detail in understanding infant pain within a caregiver context.

\section{Infant acute pain and attachment: the importance of the caregiver context}

Grounded in Attachment Theory [22,23], the DIAPR-R model emphasizes the caregiver context of infant pain as fundamental to understanding its response. Over the first year of life infants are biologically predisposed to respond in ways that are predicated on having a caregiver present. From an attachment perspective, it is purported that a newborn is born able to signal distress (e.g., crying) in order to achieve physical proximity to their caregiver and alert the caregiver to engage in distress-reducing or mitigating intervention. Alternatively, it is also theorized that parents have an innate system activated by infants' distress signals, which in turn prompts them to respond in a soothing manner that will help regulate the infants' negative affect [26]. Decades of developmental psychology research have demonstrated that repeated caregiver-child interactions in distressing situations subsequently predict children's behaviour in distressing situations, which are operationalized as attachment categorizations (specifically secure, avoidant, resistant, and disorganized). While a detailed primer on Attachment Theory is beyond the scope of the chapter, the following descriptions are offered as a quick heuristic due to its relevance to understanding not only infant pain management but infant pain assessment [27], as so 
much of assessing the need and the impact of pain management is based on overt signalling. Secure infants have learned to react vigorously to distress and are more easily regulated post-distress by a caregiver whom they have learned is generally responsive to their distress. Avoidant infants have learned to mute overt distress and attempt to avoid a caregiver because they have learned to be generally rejecting during distress. Resistant infants have learned to amplify and sustain distress signalling to help ensure proximity due to learning their caregiver can be inconsistently responsive. Finally, disorganized infants tend to respond in ways that do not appear to be organized ways of interacting with a caregiver (e.g. a complete lack of behavioural response to distress). Disorganization is often based on having interactions, during distressing situation, with their caregiver where the caregiver is perceived as frightening or otherwise atypical. Disorganization as an outcome should be of particular concern when understanding preterm infants in pain, given the allostatic stress load of repetitive painful procedures in a constrained parental caregiving context. Longitudinal research has suggested NICU infants have a higher chance of attachment disorganization [28]. Moreover, positive caregiver-infant interactions have been demonstrated to exert a buffering effect on the relationships between early neonatal pain exposure in preterm infants and subsequent cognitive functioning and mental health outcomes $[29,30]$.

\section{Importance of the caregiver context in neonatal pain management}

The above findings point to the importance of caregiver inclusion in the implementation of pain management techniques in hospital settings. This is supported by previous research indicating a positive link between maternal involvement in hospitalized infants' care and newborns' levels of stress and pain [31]. Furthermore, NICU nurses have previously pointed to their heavy workload and the lack of maternal presence in the NICU during infants' medical procedures as some of the main challenges for failing to engage in non-pharmacological pain management strategies, such as skin-to-skin contact [32]. In contrast, $87 \%$ of parents of NICU infants have reported a desire to be involved in their children's pain management and, out of those who participated in a study examining attitudes to maternal care in the NICU, $80 \%$ indicated it was a positive experience and $90 \%$ would wish to be included again [33].

\section{Non-pharmacological pain management techniques in neonates}

Previous pain management models, such as the "5P" approach [34], which denotes procedural, physical, pharmacological, psychological, and process pain management interventions, have been proven crucial in directing pain management efforts for older infants and children. However, many techniques traditionally used in older infants and children are not appropriate for preterm neonates. For example, distraction has been posited to be more effective in older infants due to the immature motor and cognitive capacities at birth [35]. Moreover, longitudinal work with term infants over vaccinations in the first year of life has suggested that younger infants keep their eyes closed longer, posited to reflect sensory overwhelm and a greater dependence on caregiving [36,37].

Rather than organize in traditional groupings such as the 5P's, owing to the unique context of infancy, the article will proceed based on how the strategies are enacted with neonates, namely proximal, distal, and procedural methods of what is mostly acute pain. However, it is important to note that many of the below strategies reflect attachment principles of proximity to caregiver and increasing feelings of safety/secureness and would be helpful regardless of whether the stressor is painful or not.

A few notes regarding the following review: due to preterm neonates comprising a large proportion of hospitalized newborns in NICUs, the bulk of the data presented below will originate from research with preterm, as opposed to full term, neonates. Therefore, the nature of the sample (preterm versus full term) will only be specified if a study is based on full term neonates. Moreover, whenever possible, the effectiveness of pain management methods on reducing neonates' pain-related reactivity (earliest reactions after the painful stimulus) versus regulation (later reactions that occur after the initial painful response) will be specified [38]. Although interrelated, the distinction of these two phases is warranted, as research has suggested that non-pharmacological pain management interventions may be more related to infants' pain levels in the regulatory phase, rather than the reactivity phase [17]. Finally, readers are drawn to a recent Cochrane Review that directly reviews the literature on 22 different non-pharmacological strategies for infant and young child procedural pain [38].

\subsection{Proximal pain management methods}

Proximal methods of pain management support newborns to achieve baseline states post-painful procedure and alleviate pain by providing soothing tactile stimuli before, during, and/or after the painful procedure. According to the Gate Control Theory [39], it may be that the signals elicited by the soothing stimuli travel up ascending pathways, inhibiting the nociceptive signals created by the noxious event, through endogenous mechanisms located along the spino-thalamic tract [40].

Pain management techniques that can be encompassed in this category include skin-to-skin contact (also known as kangaroo care), facilitated tucking (containing an infant by hand-hugging), swaddling (containing an infant with a blanket), sucking-related strategies (e.g., non-nutritive sucking on a pacifier or finger), rocking, and breastfeeding. Non-nutritive sucking, swaddling/tucking, and rocking/ holding were determined to be promising pain management interventions for full-term neonates [38]. However, age differences emerged, with non-nutritive sucking failing to relieve preterm neonates pain' reactivity. Swaddling/tucking interventions and touch/massage showed promise for preterm infants [38]. Hartley, Miller, and Gephart [41] conducted an additional review that supported these results, demonstrating the effectiveness of facilitated tucking at reducing pain in preterm newborns. The results of a randomized controlled trial on the effects of swaddling on acute pain in preterm neonates also revealed analgesic effects, with the swaddled group exhibiting lower pain scores and faster returns to baseline following a blood sampling procedure [42].

Furthermore, Pillai Riddell et al. [38] also concluded that suckingrelated interventions and facilitated tucking/swaddling were shown to be effective at alleviating pain in the reactivity stage, while suckingrelated interventions and rocking/holding demonstrated effectiveness during the regulation stage. The above findings are bolstered by a second review examining the combined effects of non-nutritive sucking on pain responses in neonates and older infants up to 4 months old. In this review, Taddio and colleagues [43] showed non-nutritive sucking to be effective in reducing infant pain-related distress.

Skin-to-skin care and co-bedding. Johnston et al. [44] concluded that skin-to-skin care is more beneficial at relieving both behavioural and physiological indicators of pain than standard care. Although the pain reduction effects of skin-to-skin care have been demonstrated, nurses have stated multiple challenges precluding them from providing this care to neonates in NICUs, such as heavy workload. Mothers' presence during acute procedures in order to provide skin-to-skin contact for their children was provided as a potential solution to this issue [32]. Another pain-management intervention related to proximity is cobedding, the action of placing multiple newborns in a singular incubator. Co-bedding has been linked to a better regulated stress response following an acute procedure in neonates, as indicated by reduced cortisol levels and faster returns to baseline physiology [45].

Breastfeeding. Shah, Herbozo, Aliwalas, and Shah [46] led a 
systematic review on the effects of breastfeeding on crying time and pain scores in full-term newborns and results revealed its effectiveness over other positioning interventions (e.g, swaddling; placing the neonate in a crib), placebos, and standard care. These findings were bolstered by another systematic review conducted in 2015 on the benefits of breastfeeding for analgesic purposes [47]. Fallah, Naserzadeh, Ferdosian, and Binesh [48] demonstrated more effective analgesia in breastfeeding compared to kangaroo care and swaddling in term neonates. Interestingly, providing newborn babies with breast milk via a syringe did not lead to the same analgesic effects as breastfeeding, potentially due to the latter reducing pain-related distress via multiple mechanisms due to the combination of holding- and sucking-related interventions with ingestion of a sweet-tasting substance [34]. This further points to the importance of including mothers in pain management implementations.

\subsection{Distal pain management methods}

Distal pain management interventions involve modifying the neonates' environment to achieve a diminished pain response and painrelated distress. This category includes strategies such as controlling the noise, lighting, and smells in the NICU.

Odours. Pillai Riddell et al. [38] found that environmental modifications, such as introducing familiar odours, were effective in relieving newborns' pain in the regulation phase.

Light. Light intensity has been shown to have negative effects on neonates in NICUs, while intermittent lighting has been associated with reductions in heart rate, strengthened biological rhythm, and better sleep quality and nutrition [49]. This concept has also been applied to research examining the potential analgesic effects of low lighting. For instance, a study exploring the effects of covering newborns' eyes during a painful procedure revealed a significant reduction in infants' behavioural pain responses solely when the pain intervention was executed after the procedure, not during [50]. However, reductions in the physiological domains of pain, such as heart rate and $\mathrm{SaO}_{2}$ levels, were not observed; therefore, further studies examining the analgesic effects of light in NICUs are warranted.

Sound/music therapy. Previous studies have attempted to analyze the analgesic effects of sounds/music therapy in NICUs, posited to reduce pain by decreasing infants' state of arousal and pain-related behavioural responses [51]. However, studies have yielded mixed results. One type of sound therapy that has demonstrated analgesic qualities in both preterm and full-term neonates has been exposure to the mother's voice $[52,53]$. Additionally, listening to classical music was shown to be effective in reducing pain responses during routine heel lances [54]. Alternatively, Badr et al. [55] discovered that exposing neonates to lullabies or to music their mothers listened to during pregnancy had a positive impact on children's behavioural measures of pain, but not physiological. Other interventions, such as exposure to intrauterine sounds such as heart rate in an attempt to reduce pain reactivity have also shown promise [56].

\subsection{Procedural pain management methods}

It is important to remind readers that avoiding unnecessary painful procedures should always be the first line of pain management. However, when medically necessary, pain management implementations can also aim to achieve pain reduction by targeting and refining the medical procedure itself. Examples of procedural pain management techniques incorporated in this classification are choosing appropriate injection sites, sequencing vaccines suitably in an attempt to reduce their additive pain in order of least painful to most painful, and using aspiration versus no aspirations during vaccines. For instance, heel lances are the most commonly used procedures in NICUs for blood sampling [57]. However, a systematic review on heel lance versus venepuncture for neonate blood sampling concluded that venepuncture yield lower pain scores on numerous validated measures of pain in fullterm neonates [58]. Moreover, research analyzing the analgesic effects of adding upper limb massage to the vaccination procedure, i.e. prior to administering venepuncture, in a sample of preterm and full-term neonates has revealed lower pain scores in those who received the massage intervention [59].

A review that combined results from newborns with infants up to 6 months old determined that, when administering multiple vaccines, injecting the most painful one last produces lower overall distress in all ages [43].

\subsection{Additive effects of combined pain management methods}

As the research on infant pain matures, the use of a no pain management control group has evolved to become unacceptable. Some studies have thus analysed the additive analgesic effects of multiple combined pain management techniques to find more optimal ways of pain management, which will be reviewed next.

Research examining the combined effects of non-nutritive sucking and sucrose indicated an additive analgesic effect of non-nutritive sucking compared to sucrose alone. Furthermore, tucking/swaddling combined with non-nutritive sucking was superior compared to nonnutritive sucking alone [38]. Combined holding-related implementations (consisting of either cuddling and back-patting or swaddling, sidelying, swinging, sucking, and shushing) administered after the painful procedure have also been shown to reduce distress in newborns and infants up to 4 months old [43]. Finally, newborns displayed fewer pain-related behaviours (i.e., grimacing, squirming, limb and truck extensions) when exposed to a combination of non-nutritive sucking, facilitated tucking, and sucrose than either of these interventions alone [60].

Compared to the combined effects of facilitated tucking, non-nutritive sucking, and oral glucose, the addition of music therapy has been linked to neonates displaying more stable physiological and behavioural responses, allowing nurses to complete the required routine procedures more efficiently [61]. Further support for the benefits of music on pain-related distress emerged from Qiu et al. [62], who examined the analgesic effects of Combined Music and Touch (CMT) intervention and concluded its effectiveness at reducing neonates' pain response as measured by the PIPP. Furthermore, Shah, Kadage, and Sinn [63] determined that, although the analgesic benefits of music therapy were comparable to those of sucrose in full term neonates, the combination of the two yielded the greatest level of pain relief.

Shah et al. [47] revealed an additive effect of breastfeeding when combined with a pharmacological pain management implementation, such as a topical anaesthetic. In NICUs where expressed breast milk was considered standard care, combining this procedure with skin-to-skin mother care was shown to be more beneficial at reducing neonates' pain [64].

Overall, it appears that combining certain pain management techniques may have stronger analgesic effects compared to administering individual techniques.

\section{Future directions}

Further research is warranted to bolster the support for the current review, particularly randomized controlled trials on adequately-powered samples that use methodological standards for interventional research. More fundamentally, current pain assessment (the bedrock of optimal pain management) is currently predicated on high levels of convergence of biological and behavioural measures of pain. However, there have been important challenges to the supposition. For instance, Slater et al. [65] revealed that, although oral sucrose was effective at reducing newborns' behavioural expressions of pain, it had no analgesic effect on the underlying nociceptive brain activity or spinal cord circuits. Jones et al. [66] have found that in high stress contexts, biological 
and behavioural relationships are not seen (in contrary to strong relationships when infants show evidence of lower stress situations). Two other papers $[50,55]$ suggested analgesic effects solely on pain-related behavioural expressions and not on the underlying physiology. Finally, it is important to recognize that there is large variability in infant pain responding. Basing the efficacy or effectiveness of any infant pain intervention by simplistically comparing group means without any disaggregation of this variability will not result in understanding the true treatment effects of an intervention [67].

\section{Concluding notes}

Given the large number of pain management techniques and the exponentially large number of potential combinations, it is impossible for any review to touch upon all these combinations. Thus, clinicians are likely best served by keeping in mind key principles of neonatal pain management as reviewed such as avoiding procedures, providing soothing tactile stimulation, helping an infant to feel contained, encouraging proximity to a caregiver before, during, and after a procedure and using pharmacological interventions that may be more apt to block or moderate nociception. Moreover, scientists are encouraged to look at challenges to current study methodologies to provide better data regarding the efficacy of different pain management techniques for infants.

\section{Practice Points}

- Hospitalized preterm neonates are frequently exposed to painful medical procedures

- Early neonatal pain exposure is linked to detrimental longterm outcomes

- Pain management methods are crucial in neonatal care

- Non-pharmacological pain management (proximal, distal, and procedural) methods have shown effectiveness at reducing neonates' pain responses

- Combining certain pain management techniques may have stronger analgesic effects compared to administering individual techniques

\section{Research Directions}

- Randomized controlled trials on adequately-powered samples analyzing the efficiency and effectiveness of pain management methods are needed

- Differentially examining the analgesic effects of pain management methods on infants' behavioural versus physiological pain responses must be conducted

- Acknowledging the large variability in infant pain responding in order to uncover the true treatment effects of interventions

\section{Conflict of interest}

The authors have no conflicts of interest to disclose.

\section{Funding statement}

Oana Bucsea is funded by the Social Sciences and Humanities Research Council of Canada and the Lillian Meighen and Don Wright Foundation. Dr. Rebecca Pillai Riddell is funded by grants from the Natural Sciences and Engineering Research Council, Social Science and Humanities Research Council, Canadian Institutes of Health Research, Canada Foundation for Innovation.

\section{References}

[1] Harrison WN, Wasserman JR, Goodman DC. Regional variations in neonatal intensive care admissions and the relationship to bed supply. J Pediatr 2018;192:73-9.

[2] Cruz MD, Fernandes AM, Oliviera CR. Epidemiology of painful procedures per formed in neonates: a systematic review of observational studies. Eur J Pain 2016;20:489-98.

[3] Carbajal R, Rousset A, Danan C, Coquery S, Nolent P, Ducrocq S, et al. Epidemiology and treatment of painful procedures in neonates in intensive care units. JAMA, J Am Med Assoc 2008;300:60-70.

[4] Britto CD, Rao S, Nesargi S, Nair S, Rao S, Thilagavathy T, et al. Pain - perception and assessment of painful procedures in the NICU. J Trop Pediatr 2014;60:422-7.

[5] Anand KJS, Craig KD. Editorial: new perspectives on the definition of pain. Pain 1996;67:3-6.

[6] Fisk NM, Gitau R, Teixeira JM, Giannakoulopoulos X, Cameron AD, Glover VA. Effect of direct fetal opiod analgesia on fetal hormonal and hemodynamic stress response to intrauterine needling. Anesthesiology 2001;95:828-35.

[7] Fitzgerald M, Shaw A, McIntosh N. Postnatal development of the cutaneous flexor reflex: comparative study of preterm infants and newborn rat pups. Dev Med Child Neurol 1988;30:520-6.

[8] Johnston C, Barrington KJ, Taddio A, Carbajal R, Filion F. Pain in Canadian NICUs: have we improved over the past 12 years? Clin J Pain 2011;27:225-32.

[9] Simons SHP, van Dijk M, Anand KJS, Roofthooft D, van Lingen RA, Tibboel D. Do we still hurt newborn babies? A prospective study of procedural pain and analgesia in neonates. Arch Pediatr Adolesc Med 2003;157:1058-64.

[10] Grunau RVE, Whitfield MF, Petrie JH, Fryer EL. Early pain experience, child and family factors as precursors of somatization: a prospective study of extremely premature and fullterm children. Pain 1994;56:353-9.

[11] Ranger M, Synnes AR, Vinall J, Grunau RE. Internalizing behaviours in school-age children born very preterm are predicted by neonatal pain and morphine exposure. Eur J Pain 2014;18:844-52.

[12] Ranger M, Chau CMY, Garg A, Woodward TS, Beg MF, Bjornson B, et al. Neonatal pain-related stress predicts cortical thickness at age 7 years in children born very preterm. PLoS One 2013;8:e76702.

[13] Slater R, Fabrizi L, Worley A, Meek J, Boyd S, Fitzgerald M. Premature infants display increased noxious-evoked neuronal activity in the brain compared to healthy age-matched term-born infants. Neuroimage 2010;52:583-9.

[14] Taddio A, Shah V, Atenafu E, Katz J. Influence of repeated painful procedures and sucrose analgesia on the development of hyperalgesia in newborn infants. Pain 2009; 144:43-8.

[15] Anand KJS. Relationships between stress responses and clinical outcomes in newborns, infants, and children. Crit Care Med 1993;21:S358-9.

[16] Goubert L, Pillai Riddell R, Simons L, Borsook D. Psychological theories and models in pediatric pain. Oxford textbook of paediatric pain. Oxford, UK: Oxford University Press; 2019. in press.

[17] Pillai Riddell R, Racine NM, Craig K, Campbell L. Psychological theories and models in pediatric pain. Oxford textbook of paediatric pain. Oxford, UK: Oxford University Press; 2013.

[18] Verrioris M, Chang P, Fitzgerald M, Fabrizi L. The development of the nociceptive brain. Neuroscience 2016;338:207-19.

[19] Eisenberg N, Cumberland A, Spinrad TL. Parental socialization of emotion. Psychol Inq 1998;9:241-73.

[20] Kopp CB. Regulation of distress and negative emotions: a developmental view. Dev Psychol 1989;25:343-54.

[21] O'Neill MC, Pillai Riddell R, Garfield H, Greenberg S. Does caregiver behaviour mediate the relationship between cultural individualism and infant pain at 12 months of age? J Pain 2016;17:1273-80.

[22] Bowlby J. Attachment and loss: I. Attachment. London: Hogarth Press; 1969.

[23] Bowlby J. Attachment and loss: retrospect and prospect. Am J Orthopsychiatry 1982;52:664-78.

[24] Ainsworth MDS, Blehar MC, Waters E, Wall S. Patterns of attachment: a psychological study of the Strange Situation. Hillsdale, NJ: Erlbaum; 1978.

[25] Main M, Solomon J. Procedures for identifying infants as disorganized/disoriented during the Ainsworth Strange Situation. In: Greenberg MT, Cicchetti D, Cummings EM, editors. Attachment in the preschool years. Chicago: University of Chicago Press; 1990. p. 121-60.

[26] Marvin RS, Brittner PA. Normative development: the ontogeny of attachment. In: Cassidy J, Shaver PR, editors. Handbook of attachment theory, research and clinical applications. New York: Guilford Press; 1999. p. 44-67.

[27] Benoit D. Infant-parent attachment: definition, types, antecedents, measurement and outcome. Pediatrics Child Health 2004;9(8):541-5.

[28] Wolke D, Eryigit-Madzwamuse S, Gutbrod T. Very preterm/very low birthweight infant's attachment: infant and maternal characteristics. Arch Dis Child Fetal Neonatal Ed 2014(99):F70-5.

[29] Tu MT, Grunau RE, Petrie-Thomas J, Haley DW, Weinberg J, Whitfield MF. Maternal stress and behaviour modulate relationships between neonatal stress, attention, and basal cortisol at 8 months in preterm infants. Dev Psychobiol 2007;49:150-64.

[30] Vinall J, Miller SP, Synnes AR, Grunau RE. Parent behaviours moderate the relationship between neonatal pain and internalizing behaviours at 18 months corrected age in children born very prematurely. Pain 2013;154:1831-9.

[31] Lester BM, Hawes K, Abar B, Sullivan M, Miller R, Bigsby R, et al. Single-family room care and neurobehavioural and medical outcomes in preterm infants. Pediatrics 2014;134:754-60. 
[32] Benoit B, Campbell-Yeo M, Johnston C, Latimer M, Caddell K, Orr T. Staff nurse utilization of kangaroo care as an intervention for procedural pain in preterm infants. Adv Neonatal Care 2016;16:229-38.

[33] Campbell-Yeo M, Johnston CC, Filion F, McNaughton K. A comparison of nurse and mother attitudes regarding maternal skin-to-skin care as a pain relieving strategy during heel lance for preterm neonates. 1st European conference on the kangaroo MotherCare proceedings. 2008.

[34] Taddio A, McMurtry M, Shah V, Pillai Riddell RR, Chambers CT, Noel M, et al. Reducing pain during vaccine injections: clinical practice guidelines. Can Med Assoc J 2015;187:975-82.

[35] Pillai Riddell RR, Taddio A, McMurtry M, Chambers C, Shah V, Noel M. Psychological interventions for vaccine injections in young children 0 to 3 years: systematic review of randomized controlled trials and quasi-randomized controlled trials. Clin J Pain 2015;31:S64-71.

[36] Ahola Kohut S, Pillai Riddell RR, Flora D, Oster H. A longitudinal analysis of the development of infant facial expressions in responses to acute pain: immediate and regulatory expressions. Pain 2012;153:2458-65.

[37] O'Neill M, Ahola Kohut S, Pillai Riddell R, Oster H. Age related differences in the acute pain facial expression during infancy. Eur J Pain 2019. (in press).

[38] Pillai Riddell RR, Racine NM, Hennis HG, Turcotte K, Uman LS, Horton RE, et al. Non-pharmacological management of infant and young child procedural pain. Cochrane Database Syst Rev 2015;12:CD006275.

[39] Melzack R, Wall PD. Pain mechanisms: a new theory. Science 1965;150:971-9.

[40] Quirion R. Pain, nociception, and spinal cord receptors. Prog Neuro-Pharmacol Biol Psychiatr 1984;8:571-9.

[41] Hartley KA, Miller CS, Gephart SM. Faciliated tucking to reduce pain in neonates: evidence for best practice. Adv Neonatal Care 2015:15:201-8.

[42] Ho LP, Ho SS, Leung DY, So WK, Chan CW. A feasibility and efficacy randomised controlled trial of swaddling for controlling procedural pain in preterm infants. J Clin Nurs 2016;25:472-82.

[43] Taddio A, Shah V, McMurtry CM, MacDonald NE, Ipp M, Pillai Riddell R, et al Procedural and physical interventions for vaccine injections: systematic review of randomized controlled trials and quasi-randomized controlled trials. Clin J Pain 2015;31:S20-37.

[44] Johnston C, Campbell-Yeo M, Disher T, Benoit B, Fernandes A, Streiner D, et al. Skin-to-skin care for procedural pain in neonates. Cochrane Database Syst Rev 2017;2:CD008435.

[45] Campbell-Yeo ML, Johnston CC, Joseph KS, Feeley N, Chambers CT, Barrington KJ, et al. Co-bedding between preterm twins attenuates stress response after heel lance: results of a randomized trial. Clin J Pain 2014;30:598-604.

[46] Shah PS, Herbozo C, Aliwalas LL, Shah VS. Breastfeeding or breast milk for procedural pain in neonates. Cochrane Database Syst Rev 2012;12:CD004950.

[47] Shah VS, Taddio A, McMurtry CM, Halperin SA, Noel M, Pillai Riddell R, et al. Pharmacological and combined interventions to reduce vaccine injection pain in children and adults: systematic review and meta-analysis. Clin J Pain 2015;31:S38-63.

[48] Fallah R, Naserzdeh N, Ferdosian F, Binesh F. Comparison of effect of kangaroo mother care breastfeeding and swaddling on Bacillus Calmetter-Guerin vaccination pain score in healthy term neonates by a clinical trial. J Matern Fetal Neonatal Med 2017;30:1147-50.

[49] Reid T, Freer Y. Developmentally focused nursing care. In: Boxwell G, editor. Neonatal intensive care nursing. second ed.London: Routledge; 2010. p. 16-9.

[50] Alemdar DK, Özdemir FK. Effects of covering the eyes versus playing intrauterine sounds on premature infants' pain and physiological parameters during venipuncture. J Pediatr Nurs 2017;37:e30-6.

[51] Cignacco E, Hamers JP, Stoffel L, van Lingen RA, Gessler P, McDougall J, et al. The efficacy of non-pharmacological interventions in the management of procedural pain in preterm and term neonates. A systematic literature review. Eur J Pain 2007;11:139-52.

[52] Azarmnejad E, Sarhangi F, Javadi M, Rejeh N. The effects of mother's voice on arterial blood sampling induced pain in neonates hospitalized in neonate intensive care unit. Glob J Health Sci 2015;7:198-204.

[53] Chirico G, Cabano R, Villa G, Bigogno A, Ardesi M, Dioni E. Randomised study showed that recorded maternal voices reduced pain in preterm infants undergoing heel lance procedures in a neonatal intensive care unit. Acta Paediatr 2017;106:1564-8.

[54] Bergomi P, Chieppi M, Maini A, Mugnos T, Spotti D, Tzialla C, et al. Nonpharmacological technoques to reduce pain in preterm infants who receive heel-lance procedure: a randomized controlled trial. Res Theor Nurs Pract: Int J 2014;28:335-48

[55] Badr LK, Demerjian T, Daaboul T, Abbas H, Zeineddine MH, Charafeddine L. Preterm infants exhibited less pain during a heel stick when they were played the same music their mothers listened to during pregnancy. Acta Paediat 2017; 106:438-45.

[56] Alemdar DK, Tüfeci G. Effects of maternal heart sounds on pain and comfort during aspiration in preterm infants. Jpn J Nurs Sci 2017;15. 330-330.

[57] Barker DP, Rutter N. Exposure to invasive procedures in neonatal intensive care unit admissions. Arch Dis Child 1995;72:F47-8.

[58] Shah VS, Ohlsson A. Venepuncture versus heel lance for blood sampling in term neonates. Cochrane Database Syst Rev 2011;10:CD001452.

[59] Chik Y, Ip W, Choi K. The effect of upper limb massage on infants' venipuncture pain. Pain Manag Nurs 2017;18:50-7.

[60] Yin T, Yang L, Lee TY, Li CC, Hua YM, Liaw JJ. Development of atraumatic heelstick procedure by combined treatment with non-nutritive sucking, oral sucrose, and facilitated tucking: a randomized, controlled trial. Int J Nurs Stud 2015;52:1288-99.

[61] Ullsten A, Eriksson M, Klässbo M, Volgsten U. Live music therapy with lullaby singing as affective support during painful procedures: a case study with microanalysis. Nord J Music Ther 2017;26:142-66.

[62] Qiu J, Jiang Y, Li F, Tong Q, Rong H, Cheng R. Effect of combined music and touch interventions on pain response and B-endorphin and cortisol concentrations in late preterm infants. BMC Pediatr 2017;17:38

[63] Shah SR, Kadage S, Sinn J. Trial of music, sucrose, and combination therapy for pain relief during heel prick procedures in neonates. J Pediatr 2017;190:153-8.

[64] Shukla VV, Bansal S, Nimbalkar A, Chapla A, Phatak A, Patel D, et al. Pain control interventions in preterm neonates: a randomized controlled trial. Indian Pediatr 2018;55:292-6.

[65] Slater R, Cornelissen L, Fabrizi L, Patten D, Yaxen J, Worley A, et al. Oral sucrose as an analgesic drug for procedural pain in newborn infants: a randomised controlled trial. Lancet 2010;376:1225-32.

[66] Jones L, Fabrizi L, Laudiano-Dray M, Whitehead K, Meek J, Verriotis M, et al Nociceptive cortical activity is dissociated from nociceptive behaviour in newborn human infants under stress. Curr Biol 2017;27:3846-51.

[67] Pillai Riddell RR, Flora DB, Stevens SA, Stevens BJ, Cohen LL, Greenberg S, et al. Variability in infant acute pain responding meaningfully obscured by Averaging Pain Responses. Pain 2013;154:714-21. 